\title{
Maternal and fetal tissue accumulation of selected endocrine disrupting compounds (EDCs) following exposure to sewage sludge-treated pastures before or after conception
}

\author{
S. M. Rhind, ${ }^{* a}$ C. E. Kyle, ${ }^{a}$ C. Mackie, ${ }^{a}$ L. McDonald,,${ }^{a}$ Z. Zhang, ${ }^{a}$ E. I. Duff, ${ }^{b}$ M. Bellingham, ${ }^{c}$ \\ M. R. Amezaga, ${ }^{d}$ B. Mandon-Pepin, ${ }^{e}$ B. Loup,${ }^{e}$ C. Cotinot $_{,}{ }^{2}$ N. P. Evans, ${ }^{c}$ R. M. Sharpe ${ }^{f}$ and P. A. Fowler ${ }^{d}$
}

Received 19th February 2010, Accepted 14th June 2010

DOI: 10.1039/c0em00009d

Liver concentrations of selected pollutant classes were determined in groups of sheep fetuses and their dams, at 55 (Experiment 1) and 110 (Experiment 2) days of gestation (term = $145 \mathrm{~d}$ ) following exposure, throughout their breeding lives and after mating, to pasture treated with either inorganic fertiliser (control, CC) or with sewage sludge (treated, TT). In a unique study designed to separate the respective contributions of environmental sources and mobilised tissue to the available EDC burden, in additional groups of animals, pollutant burdens at 110 days gestation were assessed following exposure to the respective treatments, either throughout their breeding lives until mating, but not thereafter (TC), or only between mating and slaughter (CT) (Experiment 3). With very few exceptions, maternal and fetal liver concentrations of diethylhexyl phthalate (DEHP) and selected polychlorinated biphenyls (PCBs), and polybrominated diphenyl ethers (PBDE) and polycyclic aromatic hydrocarbons (PAHs) were not significantly affected by sludge exposure in any group. In some cases, maternal and fetal tissue EDC concentrations were different but the differences were not consistent, and maternal and fetal concentrations of none of the classes of chemical were significantly correlated. It was not possible to identify a single chemical, or class of chemical, that may be responsible for previously observed physiological effects of exposure to sludge-treated pastures. It is concluded that exposure of sheep to pastures fertilised with sewage sludge was not associated with increased liver concentrations of EDCs, irrespective of the stage of development at which they were measured and of maternal tissue mobilisation and EDC release during gestation. Thus, retrospective measurements of EDC tissue burdens could not be used to accurately assess earlier fetal EDC insults.

${ }^{a}$ Macaulay Land Use Research Institute, Craigiebuckler, Aberdeen, AB15 8QH, UK. E-mail: s.rhind@macaulay.ac.uk; Fax: +44 (0) 1224 395010; Tel: +44 (0) 1224395228

${ }^{b}$ Biomathematics and Statistics, Scotland, Craigiebuckler, Aberdeen, AB15 $8 Q H$, Scotland, UK

${ }^{c}$ Division of Cell Sciences, Institute of Comparative Medicine, University of Glasgow Veterinary School, Glasgow, G61 1QH, UK

${ }^{d}$ Department of Obstetrics and Gynaecology, Institute of Medical Sciences, CLSM, University of Aberdeen, Foresterhill, Aberdeen, AB25 2ZD, UK

${ }^{e} I N R A$, UMR 1198, Biologie du Developpement et de la Reproduction, 78350 Jouy-en-Josas, France

${ }^{f}$ MRC Human Reproductive Sciences Unit, Queen's Medical Research Institute, University of Edinburgh, 47 Little France Crescent, Edinburgh, EH16 4TJ, UK

\section{Introduction}

Exposure to endocrine disrupting compounds (EDCs) is known to adversely affect many organs and physiological systems in a wide range of animal species. ${ }^{1-3}$ Effects of exposure to these compounds have been assessed through observations of wildlife exposed to abnormally high levels of single pollutants or pollutant types ${ }^{3,4}$ and by controlled, empirical studies of laboratory rodents exposed to pharmacological doses of a single compound or class of compound.5,6 Environmental EDC concentrations have been measured in some of these cases and the doses applied to laboratory animals have been defined but there have been relatively few reports of EDC concentrations in

\section{Environmental impact}

Understanding of adverse effects of endocrine disrupting compounds (EDCs) on animal health and physiology requires knowledge of the "insult" to which target tissues are exposed. Tissue concentrations are likely to differ from environmental concentrations as a result of the processes of uptake, metabolism and excretion. This study characterises maternal and fetal tissue concentrations at different gestational ages following exposures at selected times around mating and shows that tissue burdens differ between the mother and fetus, with chemical class, stage of gestation and calendar dates of exposure. These findings suggest that extrapolation from environmental measurements of exposure to tissue levels, between animals at different stages of development and between studies, even of the same design, require caution. 
the tissues of animals exposed to more normal environmental concentrations.

One exception to this is a recent set of studies in which sheep have been exposed to environmental (low) levels of multiple EDCs and potentially toxic metals (PTMs) through the application of sewage sludge to pastures. Both previously predicted and actual increases in environmental EDC/PTM concentrations following sludge applications to land $\mathrm{d}^{7,8}$ and associated increases in tissue concentrations of various classes of pollutants in animals exposed to sludge-treated pasture $^{8-12}$ are small or undetectable. Nevertheless, changes in fetal hypothalamo-pituitary $^{13}$ and gonadal physiology, ${ }^{14,15}$ fetal organ histology, ${ }^{15}$ offspring behaviour ${ }^{16}$ and adult bone structure, ${ }^{17}$ associated with maternal exposure to this low-level chemical insult, have been reported. Furthermore, some of these gonadal effects appear to persist into adulthood in the offspring. ${ }^{18}$

Understanding of the relationships between levels of environmental exposure to pollutants and physiological responses requires knowledge of the pollutant concentration in the target $\operatorname{organ}(\mathrm{s})$. However, there are relatively few reports, for any species, of the tissue concentrations of EDCs in fetuses, ${ }^{12,15,19-22}$ which is widely accepted as the stage of development most sensitive to disruption. All of these reports, except one, ${ }^{12}$ concern humans in which it is impossible to directly relate tissue concentrations to exogenous treatments. Thus, while environmental EDC levels have been measured in some studies, the need to determine the tissue concentrations associated with the induction of physiological effects in fetuses remains. ${ }^{23}$ Concentrations of EDCs in placental tissue, umbilical cord blood, or fetal fluids can be determined ${ }^{24,25}$ but these represent concentrations, in vivo, before the processes of uptake, excretion and metabolism by the fetus or neonate have occurred and therefore their value as indices of early life tissue exposure is limited.

In a previous sheep study, ${ }^{12}$ the relationship between exposure and fetal tissue concentrations was investigated at a relatively late stage of gestation (110 days) by which time many developmental processes have been completed. However, many major developmental processes, and associated changes in gene or protein expression, occur during earlier developmental stages and so knowledge of the EDC insult at such times is required if relationships between tissue concentrations and physiological responses are to be determined. The first objective of the current studies was to determine the maternal and fetal burdens of different pollutant classes, in sheep, at a much earlier stage of placental and fetal development (55 days of gestation), following maternal exposure to environmental concentrations of pollutants through the application of sewage sludge fertiliser to their pasture.

During gestation, the increased nutrient demands for fetal development are met from both dietary sources and from the mobilisation of maternal adipose tissue reserves, particularly during the later stages when fetal growth is greatest. Such mobilisation can result in the release of EDCs from the mobilised fat and additional fetal exposure. ${ }^{26}$ However, the relative contributions of pollutants released from maternal tissues during gestation and of pollutants derived contemporaneously from maternal dietary/inhalation exposure are currently unknown. It is of concern that the relative risks associated with exposures from the respective EDC sources cannot be assessed. Therefore, the novel second objective was to determine the effect on tissue EDC burden of exposure of pregnant ewes to sludge-treated pastures either before mating, only (fetal exposure above background levels only as a result of release of accumulated EDCs from mobilised maternal tissue), or during gestation, only (fetal exposure above background levels as a result of environmental inputs).

While, ideally, the concentrations of EDCs would be assessed in tissues susceptible to their effects (e.g. gonad), the amounts of tissue required for analysis preclude this until far more sensitive techniques are developed. Similarly, while fat is often considered to be the most significant body store for EDCs and might therefore be considered an appropriate target tissue for EDC measurement, early fetal fat depots are very small and insufficient for analysis. On the other hand, measurements of liver tissue concentrations are more closely related to measures of toxicity than environmental exposure measurements. ${ }^{27}$ The liver is an important organ, the function of which is susceptible to pollutants; it is a component of human diet and is available in relatively large amounts in both the dam and fetus; it was therefore chosen as the tissue for analysis.

\section{Material and methods}

\section{Experimental animals and management}

Animals used in this study were derived from a single flock of Texel ewes maintained at the Macaulay Institute research station (Hartwood, Lanarkshire, Scotland, UK). For each study, experimental animals were maintained, at conventional stocking rates, on the same areas of pasture, treated twice annually (early spring and late summer) with thermally dried digested sewage sludge (2.25 metric tons of dry matter per hectare; treated, T) or with inorganic fertiliser containing equivalent amounts of nitrogen (225 kg ha ${ }^{-1}$ per year; control, C). T animals were not allowed to graze this pasture until a minimum of 3 weeks after each sludge application, as prescribed by relevant legislation. ${ }^{28}$ Additional animals were added or removed from the respective plots according to pasture height, so that animals from the respective treatments were maintained in comparable nutritional states, as described previously. ${ }^{14}$ None of the ewes received supplementary feeding during the studies or at any other time during their breeding lives. The animals were inspected by a qualified shepherd on a daily basis and routine animal care and vaccination procedures were conducted, as prescribed by best practice protocols.

Ewes used in the studies were synchronised in oestrus, using progestagen sponges (chronolone, $30 \mathrm{mg}$; Intervet, Cambridge, UK), before being mated, naturally, to Texel rams, at the second oestrus following sponge withdrawal during the normal breeding season (October/November).

\section{Soil EDC concentrations}

Soil cores ( $5 \mathrm{~cm}$ diameter and $5 \mathrm{~cm}$ depth) were collected from approximately 40 sites within each of the treated and control pastures at 2 to 4 weeks before ewes were mated. Samples from within each of the respective plots were pooled and analysed for selected EDCs to provide an index of EDC exposure. 
Experiment 1. Multiparous ewes ages 4-6 years which had been maintained on the respective treatments throughout their breeding lives were used. Approximately 5 months after the most recent sludge application to the treated pasture, multiparous, pregnant ewes ( $n=12$ per treatment), at 55 days of gestation, were euthanased according to Schedule 1 protocols, as defined by the UK Animals (Scientific Procedures) Act, 1986. This time point represents a stage of gestation at which maternal tissue mobilisation is normally minimal but fetal gonadal growth and development are significant. Liver tissues were collected from all ewes and fetuses, wrapped in aluminium foil, and stored at $-20{ }^{\circ} \mathrm{C}$, within about 15 minutes of slaughter, until analysis.

Experiments 2 and 3. These studies were designed to show the relative contributions to tissue burdens of contemporary (days 0 110 of gestation) and historical (up to the time of conception) maternal EDC exposure. Ewes similar to those used in Experiment 1 were slaughtered at 110 days of gestation having been exposed to sludge-treated or control pastures, either before and/ or after mating. Two separate groups of ewes were exposed to each of the sludge and control treatments. Within the first group (Expt 2: continuous treatment), sludge-exposed animals were maintained on the sludge-treated pasture throughout their breeding lives up to the time of mating and also during gestation, until the time of slaughter (TT, $n=12$ ), while control animals (CC, $n=12$ ) were maintained on pastures treated with inorganic fertiliser, both before and after mating.

A second group of ewes (Expt 3: crossover treatment) comprised animals maintained on sludge-treated pastures throughout their breeding lives, up to the time of mating but transferred thereafter to the control pastures (TC, $n=12$ ), while others were maintained on control pastures until mating and then transferred to the sludge-treated pastures (CT, $n=12)$. TC animals were transferred for a period of 10 days to a nonexperimental, uncontaminated pasture area, 4 days before the introduction of the rams. After this time they were returned to the control pasture; this protocol was designed to minimise contamination of experimental control pastures with pollutantcontaining faeces and urine and to minimise exposure of TC animals to diet-associated pollutants at conception. Similarly, animals that had previously been maintained on control pastures were transferred to the sludge-treated pastures 4 days before the introduction of the rams so that the developing embryos were likely to be exposed to diet-associated pollutants from the time of conception.

All animals in Experiments 2 and 3 were bred within a period of approximately 2 weeks and so were exposed to similar conditions of pasture height and contamination.

Maternal liver and liver from one fetus from each ewe were collected at 110 days gestation and stored for analysis, as described in Experiment 1.

\section{Monitoring of pasture and animals}

Concentrations of selected EDCs were determined using soil samples from the respective treatments to provide indices of animal exposure during the study.

Ewe liveweights and body condition scores were determined for the 110 day slaughter groups, before mating and at slaughter, in order to define the animals' nutritional state, during a period of increasing nutrient demand from the fetuses. Weights were recorded only at slaughter for animals slaughtered at 55 days because pregnancy-related changes in nutritional demand were expected to be trivial during this exposure period.

\section{Determination of tissue EDC concentrations}

Owing to the small size of 55 day fetal tissues, it was necessary to pool livers from two or three animals within the same treatment group to provide sufficient material for analyses. In spite of this, there was insufficient material for the final determinations (phthalate and PAHs) in all of the pooled samples. Samples from each 110 day fetus were analysed separately.

\section{Sample preparation (extraction and clean-up)}

PCB and PBDE. Soil samples (approximately $1 \mathrm{~g}$ dry weight) were spiked with $0.01 \mu \mathrm{g}$ internal standards of ${ }^{13} \mathrm{C}$ polychlorinated biphenyl (PCB) 138 and ${ }^{13} \mathrm{C}$ polybrominated diphenyl ether (PBDE) 99 and extracted by Dionex ASE 200. (Solvents: dichloromethane. Temperatures: $120{ }^{\circ} \mathrm{C}$. Pressure: 1500 psi. Static time duration: 5 minutes. Flush volume $60 \%$ and purge 60 seconds.) The extracts were then concentrated to $0.5 \mathrm{ml}$ under a gentle stream of nitrogen. Sample clean-up was achieved using absorption chromatography, primarily; the extracts were loaded onto a $5 \mathrm{~g}$ silica, $10 \mathrm{~g}$ of acid modified $(2: 1$, silica : sulfuric acid) silica and $1 \mathrm{~g}$ anhydrous $\mathrm{Na}_{2} \mathrm{SO}_{4}$ column (25 cm length, $15 \mathrm{~mm}$ id, fitted with PTFE taps), conditioned with $40 \mathrm{ml}$ isohexane. Sample was loaded and eluted by $20 \mathrm{ml}$ isohexane which was discarded, and then eluted by $80 \mathrm{ml}$ of isohexane which was collected. The collected solvent was evaporated to near dryness using a rotary-evaporator and then transferred to clear GC vials for the instrumental analysis.

Concentrations in tissue were determined according to protocols described previously. ${ }^{12}$ Briefly, internal standards were added to $1 \mathrm{~g}$ tissue samples followed by extraction with dichloromethane : isohexane (v/v $1: 1)$ at $55^{\circ} \mathrm{C}$ for two hours. The extract was filtered and evaporated under nitrogen. The sample clean-up was achieved by absorption chromatography ( $10 \mathrm{~g}$ acid modified silica column which was conditioned by $40 \mathrm{ml}$ isohexane). The elute (100 $\mathrm{ml}$ isohexane) was collected and concentrated by rotary-evaporation and gentle nitrogen flow and transferred to GC vials, ready for further analysis.

PAHs. Concentrations of 16 EPA-priority polycyclic aromatic hydrocarbons (PAHs) were determined in tissue and soils according to methods described previously ${ }^{12}$, as follows: $1 \mathrm{~g}$ of dry sample was spiked with 7 deuterated internal standards (d-8 naphthalene, d-10 acenaphthene, d-10 fluorene, d-10 phenanthrene, $\mathrm{d}-10$ anthracene, $\mathrm{d}-10$ pyrene and $\mathrm{d}-12$ chrysene) and $8 \mathrm{ml}$ ethanoic potassium hydroxide $(1 \mathrm{M})$ added. It was heated at approximately $90{ }^{\circ} \mathrm{C}$ for 8 hours. The samples were allowed to cool and $2 \mathrm{ml}$ of Milli-Q water added. Samples were extracted into $3 \times 10 \mathrm{ml}$ isohexane. The extracts were then concentrated to $0.5 \mathrm{ml}$ under a gentle stream of nitrogen. Sample clean-up was achieved using absorption chromatography. The extracts were loaded onto a $9 \mathrm{~g}$ silica, $1 \mathrm{~g}$ of acid modified silica and $1 \mathrm{~g}$ anhydrous $\mathrm{Na}_{2} \mathrm{SO}_{4}$ column $(25 \mathrm{~cm}$ length, $15 \mathrm{~mm}$ id, fitted with 
PTFE taps), conditioned with $40 \mathrm{ml}$ isohexane. Sample was loaded and eluted by $10 \mathrm{ml}$ discarded DCM : isohexane $(1: 4)$, and then eluted for collection by $40 \mathrm{ml}$ of $1: 4 \mathrm{DCM}$ : isohexane. The fractions collected were concentrated to $0.1 \mathrm{ml}$ by rotaryevaporation and under a gentle stream of nitrogen before analysis by GC-MS.

DEHP. Soil samples (approximately $1 \mathrm{~g}$ dry weight) were spiked with $4 \mu \mathrm{g}$ internal standards of $\mathrm{d}^{4}$-diethylhexyl phthalate (DEHP) and then extracted by Dionex ASE 200. (Solvents: dichloromethane. Temperatures: $100{ }^{\circ} \mathrm{C}$. Pressure: 1500 psi. Static time duration: 5 minutes. Flush volume $60 \%$ and purge 60 seconds.) The extracts were dried down under a gentle stream of nitrogen and then re-dissolved in $0.5 \mathrm{ml}$ isohexane. Sample cleanup was achieved using solid phase extraction (SPE) Strata $\mathrm{NH}_{2}$ columns $(1 \mathrm{~g}$ per $6 \mathrm{ml})$ pre-washed by diethyl ether. The column was conditioned with $10 \mathrm{ml}$ of isohexane and the samples were loaded and then eluted by $12 \mathrm{ml}$ discarded isohexane followed by $16 \mathrm{ml} 10 \%$ diethyl ether in isohexane for collection. The collected fraction was condensed to a small volume under nitrogen gas and then transferred to clear GC vials for further analysis. Concentrations in tissue were determined according to protocols described previously. ${ }^{12}$ Briefly, $0.8 \mathrm{~g}$ of tissue samples were spiked with internal standard ( $\mathrm{d}^{4}$-DEHP) and then extracted at $50{ }^{\circ} \mathrm{C}$ for two hours. The samples were filtered and evaporated to dryness under nitrogen and re-dissolved in isohexane. Sample clean-up was conducted according to the protocols described above for soils.

\section{Instrumental analysis}

The instrument used for the analysis of these compounds was a Thermo Electron Trace MS (Hemel Hempstead, UK) linked to a Trace 2000 GC fitted with an AS2000 autosampler. Separations were effected on a Zebron ZB5 fused silica capillary column (30 $\mathrm{m} \times 0.25 \mathrm{~mm}$ (id)) coated with $95 \%$ dimethylpolysiloxane $/ 5 \%$ phenyl with a phase thickness of $0.25 \mathrm{~mm}$ (Phenomenex, Macclesfield, UK).

The oven temperature programme for PCB analysis started at $120{ }^{\circ} \mathrm{C}$ for 1 minute; the temperature was then ramped at $4{ }^{\circ} \mathrm{C}$ $\mathrm{min}^{-1}$ to $280^{\circ} \mathrm{C}$ and held for 1 minute and then ramped to $320^{\circ} \mathrm{C}$ at $30^{\circ} \mathrm{C} \mathrm{min}^{-1}$ and held for 5 minutes. For PBDE, the analysis started at $70{ }^{\circ} \mathrm{C}$ for 1 minute; the temperature was then ramped at $30^{\circ} \mathrm{C} \mathrm{min}{ }^{-1}$ to $170^{\circ} \mathrm{C}$ and then ramped to $300^{\circ} \mathrm{C}$ at $8{ }^{\circ} \mathrm{C} \mathrm{min}^{-1}$ and held for 5 minutes. For PAH, the temperature started at $70{ }^{\circ} \mathrm{C}$ for 3 minute; it was then ramped at $5{ }^{\circ} \mathrm{C} \mathrm{min}^{-1}$ to $250^{\circ} \mathrm{C}$ and held for 1 minute, ramped to $300{ }^{\circ} \mathrm{C}$ at $6{ }^{\circ} \mathrm{C} \mathrm{min}^{-1}$ and held for 6 minutes and finally ramped to $325^{\circ} \mathrm{C}$ at $10{ }^{\circ} \mathrm{C} \mathrm{min}{ }^{-1}$ and held for 5 minutes. For DEHP, the analysis started at $150^{\circ} \mathrm{C}$ for 1 minute; it was then ramped at $7{ }^{\circ} \mathrm{C} \mathrm{min}-1$ to $198{ }^{\circ} \mathrm{C}$, then ramped to $290^{\circ} \mathrm{C}$ at $15^{\circ} \mathrm{C} \mathrm{min}^{-1}$ and finally to $330^{\circ} \mathrm{C}$ at $50^{\circ} \mathrm{C}$ $\min ^{-1}$ and held for 5 minutes.

Helium was used as the carrier gas and samples were injected on to the GC column in splitless mode with a surge for PCBs/ PBDEs and PAHs while in split (with split ratio of $10: 1$ ) for DEHP. The mass spectrometer was operated in the electron ionization $\left(\mathrm{EI}^{+}\right)$mode at 70 electron volts and a source temperature of $200{ }^{\circ} \mathrm{C}$ for PCBs/PBDEs and DEHP and $250{ }^{\circ} \mathrm{C}$ for PAHs.

\section{Quality control}

To minimise any contamination, all glassware were muffled at $450{ }^{\circ} \mathrm{C}$ prior to use. All the solvents used were of HPLC glade. A procedural blank was run in parallel with every batch of 8 samples and the results were corrected accordingly. Reproducibility of the method was monitored by repeated analysis of spiked samples. The mean recoveries were $72.6-100.6 \%$ for all PCB/PBDEs (with associated RSD: $14-23 \%$ ), $82.4-99.1 \%$ for PAHs (RSD: $14-28 \%$ ), and $94 \%$ for DEHP (RSD: $10 \%$ ). The limit of detection (lod) was calculated by dilution of a quality control sample until it was no longer detectable by gas chromatography mass spectroscopy. It was $0.02 \mu \mathrm{g} \mathrm{kg}^{-1}$ for all PCBs, $0.02 \mu \mathrm{g} \mathrm{kg}^{-1}$ for PBDE 28, 47, 99 and 100 and $0.5 \mu \mathrm{g} \mathrm{kg}^{-1}$ for PBDE 153, 154 and 183, $0.01 \mu \mathrm{g} \mathrm{g}^{-1}$ for DEHP, $1 \mu \mathrm{g} \mathrm{kg}^{-1}$ for all PAHs except phenanthrene, fluoranthene, benzo[ $k]$ fluoranthene, indenol[1,2,3-cd] pyrene and dibenzo $[a, h]$ anthracene for which they were $5 \mu \mathrm{g} \mathrm{kg}^{-1}$ and pyrene for which it was $15 \mu \mathrm{g} \mathrm{kg}^{-1}$. The internal standards ${ }^{13} \mathrm{C}-\mathrm{PCB} 138,{ }^{13} \mathrm{C}$ PBDE 99, d-8 naphthalene, d-10 acenaphthene, d-10 fluorene, d-10 phenanthrene, d-10 anthracene, d-10 pyrene and d-12 chrysene, and $\mathrm{d}^{4}$-DEHP were used to compensate for losses involved in the sample extraction and work-up, to further improve the analytical quality.

The method was validated by analysis of certified reference materials (CRMs). For the 7 PCBs a sample of pork fat (ERM BB445 (Greyhound Chromatography, Birkenhead, UK)) was used and for the 7 PBDEs a sample of fish tissue (WMF-01 (Greyhound Chromatography, Birkenhead, UK)) was used. The mean value for each PCB congener of the pork CRM was 0.0133 $\mu \mathrm{g} \mathrm{g}^{-1}$ and the recoveries for the PCB congeners ranged from 55.7 to $113.9 \%$. The PBDE concentrations of the fish CRM ranged from 0.0005 to $0.1232 \mu \mathrm{g} \mathrm{g}^{-1}$ depending on the individual congener. The recoveries for the PBDEs were between 90.2 and $120.0 \%$. Congener 183 was below the limit of detection. Also the laboratory successfully participated in an inter-laboratory comparison study of phthalates in sunflower oil organised by the FAPAS, Central Science Laboratory (The Food and Environmental Research Agency, York, UK) in 2008. The $Z$-scores for two phthalate compounds (diisodecyl phthalate and benzylbutyl phthalate) were 0 and -0.1 , which further validated the laboratory performance.

\section{Statistical analyses}

For the purpose of statistical analysis, where concentrations were below measurable levels, values were arbitrarily deemed to be half of the limit of detection. All data were transformed before analysis to $\log _{10}$ values to correct for skewed distribution. Where values of $<1$ were recorded, a $\log ($ value +1$)$ transformation was applied to the variable. Data were analysed by analysis of variance assessing the effects of treatment (55 day tissues), treatment and age (110 day, maternal vs. fetal and blocking by ewe/fetus pair) and treatment and sex (110 day fetal tissues). The above analyses were conducted using Genstat for Windows release $6 .{ }^{29}$

Stepwise discriminant analysis was used to select, according to specified thresholds, subsets of concentration variables which are considered important in discriminating between treatment groups (e.g. control and treated). To investigate the effects of multiple samples recorded at the limit of detection (lod) on the 
process of selection of variables, values at the lod were replaced by random values between zero and lod, simulated from a Uniform distribution $U(0$, lod $)$. This procedure was repeated ten times and stepwise discriminant analyses carried out on each of the ten simulated datasets in order to try to establish any general trend in selection of variables. Within the stepwise procedure, settings specified to guide the process of selection and removal of variables were F-to-enter $=10 \%$ and F-to-remove $=$ $10 \%$. Separate analyses were run for maternal and fetal datasets. Concentrations were log transformed prior to analysis, which was carried out using SAS software.

\section{Results}

\section{Soil EDC concentrations}

Mean concentrations of selected EDCs in pooled soil samples collected from each of the experimental plots (treated and control) on which animals of all groups were maintained are summarised in Table 1.

\section{Ewe liveweights and body condition scores}

All groups of ewes in Experiments 2 and 3 had similar mean liveweights and condition scores, both at mating and at slaughter

Table 1 Concentrations of selected PCBs and PBDEs (ng kg-1 dry matter) and PAHs and DEHP ( $\mu \mathrm{g} \mathrm{kg} \mathrm{kg}^{-1}$ dry matter) in soil (pooled samples from approximately 40 cores per treatment) from pastures treated with inorganic fertiliser or sewage sludge. $\mathrm{ND}=$ not detectable

\begin{tabular}{|c|c|c|}
\hline Chemical & Sludge-treated & $\begin{array}{l}\text { Inorganic } \\
\text { fertiliser-treated }\end{array}$ \\
\hline \multicolumn{3}{|l|}{$\mathrm{PCB}$} \\
\hline 28 & 322 & 614 \\
\hline 52 & ND & ND \\
\hline 101 & 35.5 & 42.9 \\
\hline 118 & 20.5 & 18.4 \\
\hline 138 & 43.3 & 37.0 \\
\hline 153 & 320 & 176 \\
\hline 180 & 403 & 344 \\
\hline \multicolumn{3}{|l|}{ PBDE } \\
\hline 28 & ND & ND \\
\hline 47 & 3409 & 1439 \\
\hline 99 & 3402 & 1667 \\
\hline 100 & 209 & 95.7 \\
\hline 153 & ND & 641 \\
\hline 154 & ND & ND \\
\hline 183 & ND & ND \\
\hline \multicolumn{3}{|l|}{ PAH } \\
\hline Naphthalene & 17.9 & 18.4 \\
\hline Acenaphthalene & 1.07 & ND \\
\hline Acenaphthene & 1.74 & 4.83 \\
\hline Fluorene & 3.09 & 3.19 \\
\hline Phenanthrene & 60.3 & 80.4 \\
\hline Anthracene & 4.22 & 1.90 \\
\hline Fluoranthene & 102 & 199 \\
\hline Pyrene & 74.6 & 125 \\
\hline Benzo $[a]$ anthracene & 43.2 & 63.0 \\
\hline Chrysene & 82.2 & 111 \\
\hline Benzo[b]fluoranthene & 98.6 & 125 \\
\hline Benzo[ $k]$ fluoranthene & 43.0 & 58.1 \\
\hline Benzo $[a]$ pyrene & 74.3 & 46.7 \\
\hline Indeno $[1,2,3-c d]$ pyrene & 37.0 & 39.4 \\
\hline Dibenzo $[a, h]$ anthracene & 5.50 & 7.39 \\
\hline Benzo $[g h l]$ perylene & 45.2 & 37.9 \\
\hline DEHP & 200 & 65.4 \\
\hline
\end{tabular}

(Table 2) and animals of all groups declined to a similar mean condition score during gestation.

\section{Tissue EDC concentrations (all experiments)}

While there were few significant differences in tissue EDC concentrations with treatment, there were some consistent trends. DEHP was non-significantly lower (approximately 50\%) in continuously exposed adult animals (Fig. 1a and 2a) but not in those subjected only to post-mating exposure (Fig. 3a). Amongst the PCB congeners, $71 \%$ of mean PCB congener values were nonsignificantly higher in $\mathrm{T}$ than $\mathrm{C}$ ewe tissue of 55 day (Fig. 1b) and 110 day (Fig. 2b) groups but the reverse trend was found in $86 \%$ of values for fetal tissues (Fig. If and 2b). Amongst crossover animal tissues, $42 \%$ (adult) and 71\% (fetal) of values were nonsignificantly higher in tissues of animals on treated pasture immediately before slaughter (Fig. 3b).

The four PBDE congeners that were detected in most tissues exhibited no consistent trends (Fig. 1c and g, 2c and 3c) and PAH values (where detectable in most individuals) also exhibited no obvious trend with respect to treatment (Fig. 1d and h, 2d and 3d).

\section{Day slaughter group}

Maternal tissue EDC concentrations. Mean tissue concentrations of each of the categories of pollutant measured were low and, for some individual animals or compounds, were not detectable (Fig. 1a-d). There were no differences with treatment in tissue levels of DEHP, PCBs and PBDEs and amongst the PAHs, only naphthalene differed, being significantly higher in control than in treated animals $(P<0.05)$.

Fetal tissue EDC concentrations. Owing to the extremely small amounts of tissue available, relative to the amounts required for EDC analysis, the mean values for fetal liver were based on pooled samples, each of which was derived from several fetuses of the same treatment groups but from more than one dam $(6 \mathrm{C}$, $7 \mathrm{~T}$ ); there was not sufficient pooled sample for all determinations and so sample numbers were lower for DEHP and PAHs (4 C, $7 \mathrm{~T}$ ). Thus, neither the individual fetal data nor pooled results could be compared directly to concentrations in the corresponding dams at this stage of gestation and comparison of the two sexes was not possible. However, subjective observations

Table 2 Mean ( \pm s.e.) liveweights $(\mathrm{kg})$ and condition scores (scale: $0-5$ ) of ewes before mating and at slaughter ( 55 or 110 days gestation)

\begin{tabular}{|c|c|c|c|c|}
\hline & \multicolumn{2}{|c|}{ Before mating } & \multicolumn{2}{|l|}{ Slaughter } \\
\hline & Liveweight & $\begin{array}{l}\text { Body } \\
\text { condition }\end{array}$ & Liveweight & $\begin{array}{l}\text { Body } \\
\text { condition }\end{array}$ \\
\hline$n$ & 12 & 12 & 12 & 12 \\
\hline \multicolumn{5}{|c|}{55 days } \\
\hline $\mathrm{T}$ & & & $81.2 \pm 1.83$ & $2.7 \pm 0.080$ \\
\hline $\mathrm{C}$ & & & $83.0 \pm 2.28$ & $2.9 \pm 0.145$ \\
\hline \multicolumn{5}{|l|}{110 days } \\
\hline $\mathrm{CC}$ & $80.3 \pm 4.89$ & $3.1 \pm 0.21$ & $87.8 \pm 2.51$ & $2.6 \pm 0.12$ \\
\hline TT & $89.1 \pm 3.63$ & $3.2 \pm 0.19$ & $81.8 \pm 3.71$ & $2.3 \pm 0.08$ \\
\hline $\mathrm{TC}$ & $85.3 \pm 3.60$ & $3.3 \pm 0.14$ & $88.2 \pm 1.27$ & $2.5 \pm 0.06$ \\
\hline $\mathrm{CT}$ & $85.7 \pm 2.96$ & $2.9 \pm 0.10$ & $80.8 \pm 2.58$ & $2.4 \pm 0.05$ \\
\hline
\end{tabular}



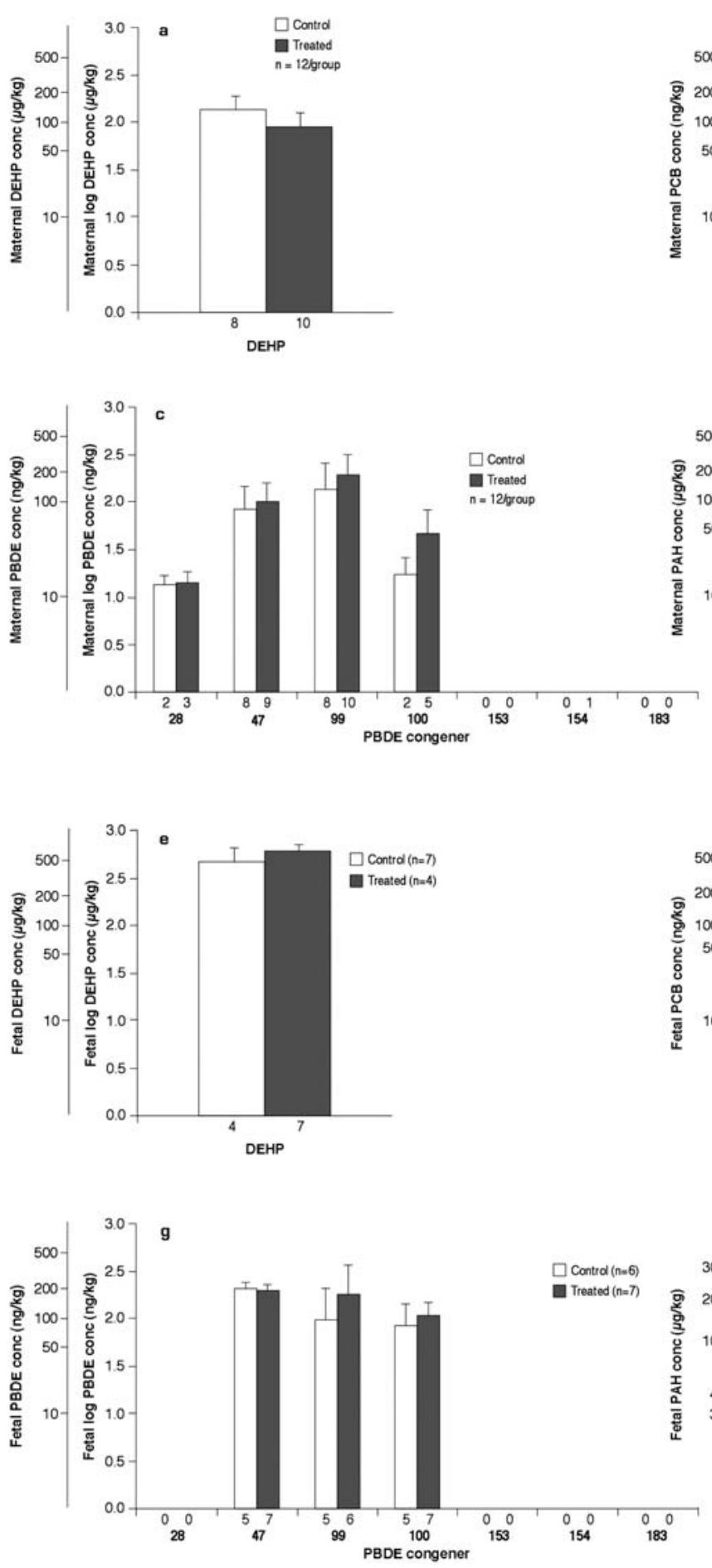
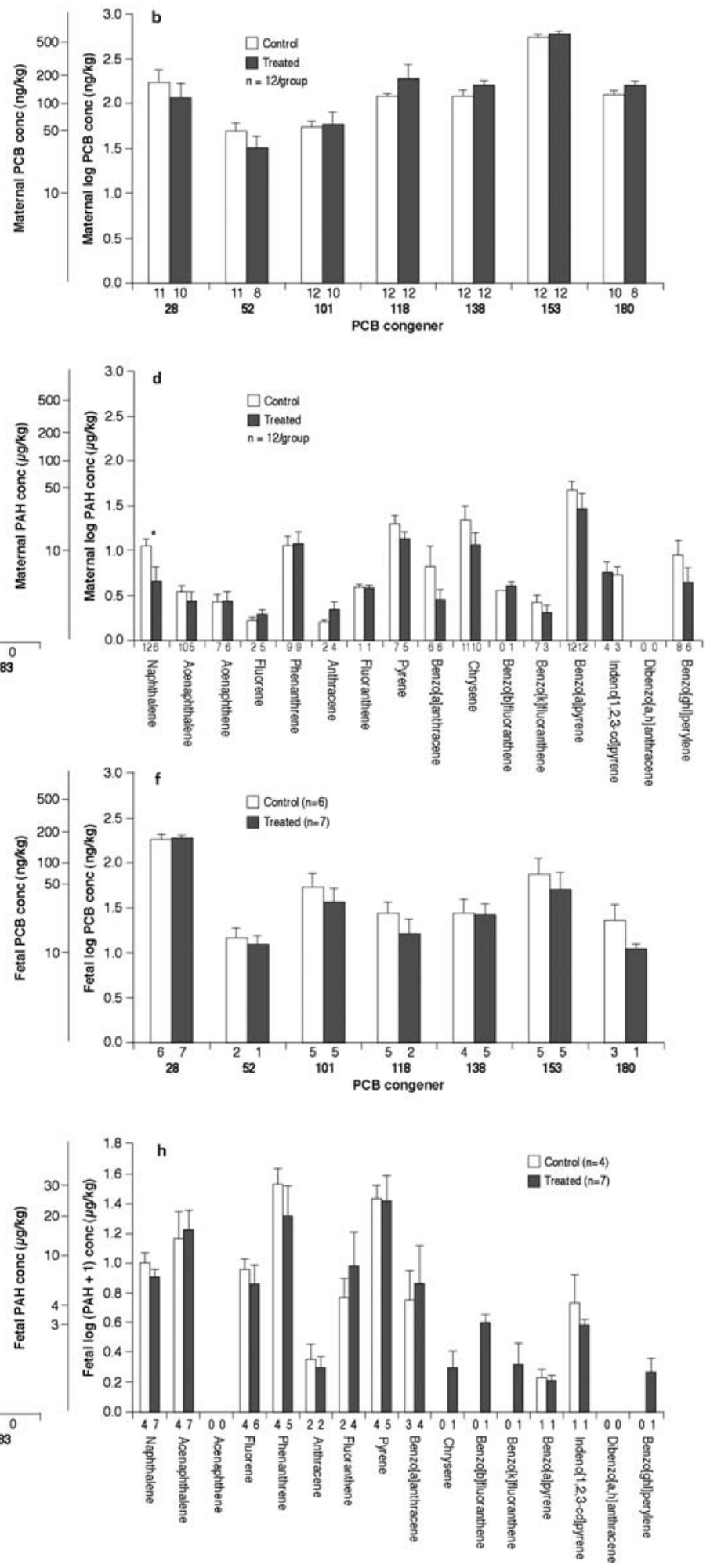

Fig. 1 Mean (+s.e.) maternal and fetal liver tissue concentrations of DEHP (a and e), PCBs (b and f), PBDEs (c and g) and PAHs (d and h) at 55 days gestation in ewes reared on pastures fertilized with sewage sludge (treated, T) or inorganic fertilizer (control, C). The numbers of individual tissues in each group in which the respective compounds were detectable are given below each bar.

indicated that mean DEHP concentrations were about 3 fold higher in 55 day fetal tissue (Fig. 1e) than in maternal tissue (Fig. 1a) while PCBs were 3 to 5 fold higher in maternal tissue for all congeners apart from 28 and 101 (Fig. $1 \mathrm{~b}$ and f). PBDEs and
PAHs values did not exhibit a consistent difference (Fig. 1c, d, g, and $h$ ).

DEHP was detected in all pooled samples but, as in maternal tissue, concentrations of some other compounds were below the 

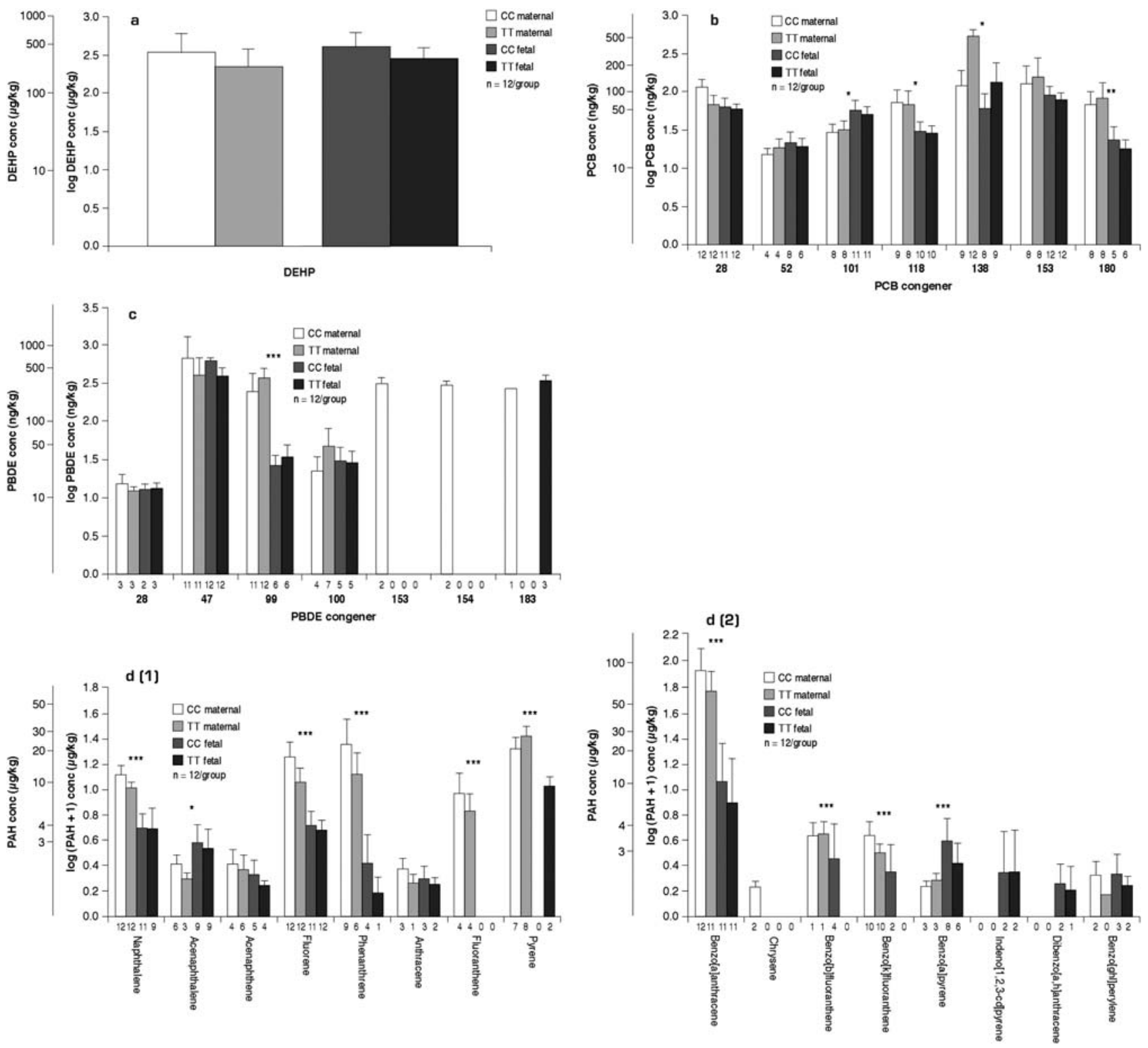

Fig. 2 Mean (+s.e.) maternal and fetal liver tissue concentrations of (a) DEHP, (b) PCBs, (c) PBDEs and (d) PAHs at 110 days gestation in ewes reared on pastures fertilized with sewage sludge (treated, TT) or inorganic fertilizer (control, CC) and maintained on the same pasture type after mating. The numbers of individual tissues in each group in which the respective compounds were detectable are given below each bar. Statistically significant differences with age (maternal vs. fetal) are indicated; few significant differences with treatment were detected (see text).

limit of detection for some individual animals or compounds (Fig. 1e-h). In particular, only PBDE congeners 47, 99 and 100 were detected in all tissues but the PAHs, acenaphthalene, chrysene and all PAHs with higher molecular weights were at or below the limit of detection in all, or almost all, of the pooled samples (Fig. 1h). There were no significant differences with treatment in tissue concentrations of any of the compounds measured at 55 days gestation.

\section{Day slaughter groups}

Direct comparisons of tissue EDC concentrations were made only within mating groups (continuous exposure: Experiment 2) and (crossover: Experiment 3). Animals of the respective groups were not directly comparable owing to the fact that they were exposed to the experimental pastures at slightly different times. However, subjective observation indicated that mean concentrations of PBDEs and PAHs were generally higher in continuously exposed (Experiment 2) animals than in Crossover (Experiment 3) animals while the reverse trend was observed in PCBs and adult, but not fetal, DEHP concentrations.

Maternal tissue EDC concentrations. The incidences of tissues with measurable amounts of compound or congener are indicated in the respective figures. While DEHP (Fig. 2a and 3a) and PCBs (Fig. 2b and 3b) were detected in most individuals, maternal liver concentrations of PBDE congeners 153, 154 and 183 (Fig. 2c and 3c) were below limits of detection in almost all 

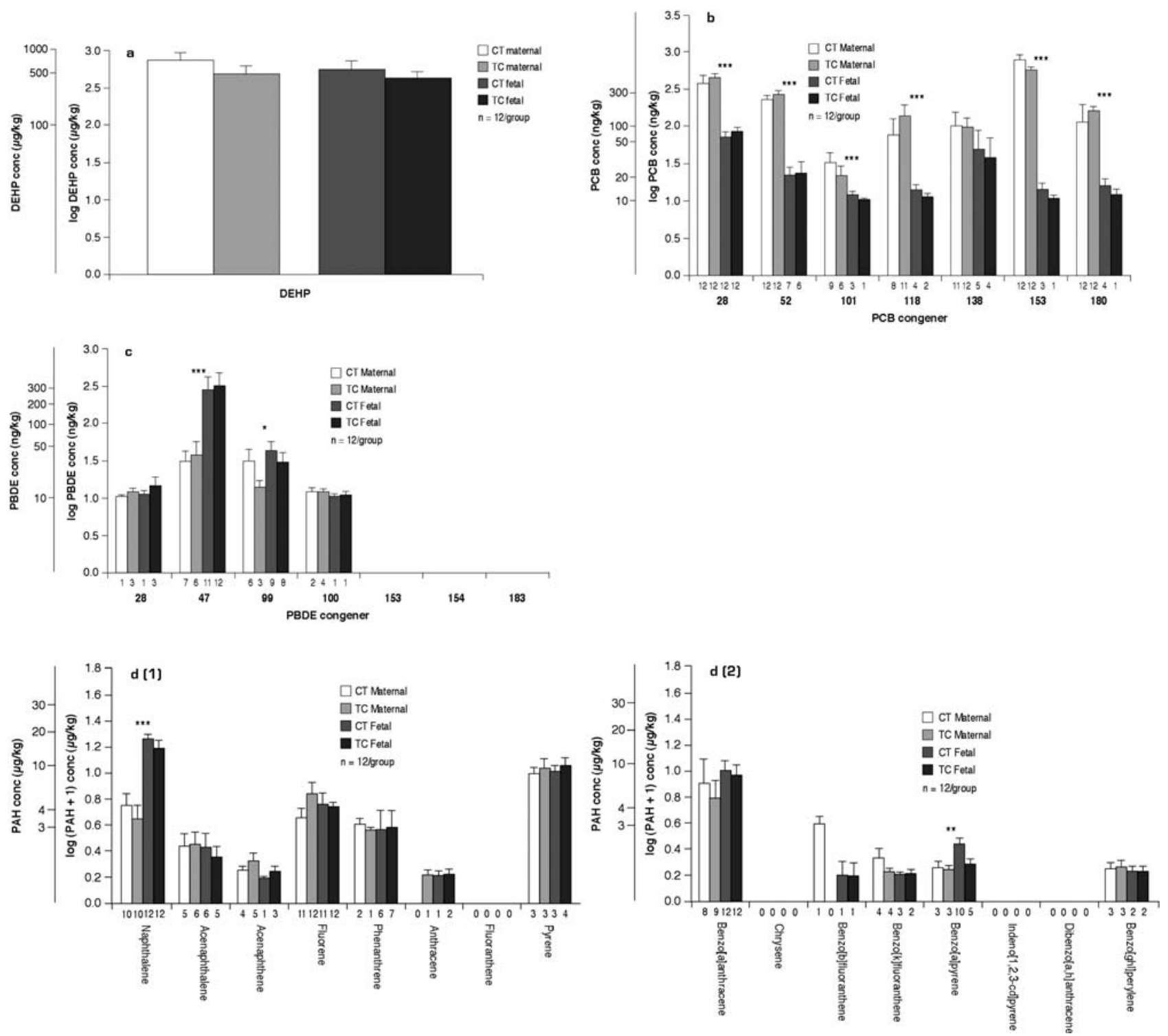

Fig. 3 Mean (+s.e.) maternal and fetal liver tissue concentrations of (a) DEHP, (b) PCBs, (c) PBDEs and (d) PAHs at 110 days gestation in ewes reared on pastures fertilized with sewage sludge (treated, TC) or inorganic fertilizer (control, CT) and switched to the opposite pasture type after mating. The numbers of individual tissues in each group in which the respective compounds were detectable are given below each bar. Statistically significant differences with age (maternal $v$ s. fetal) are indicated; few significant differences with treatment were detected (see text).

individuals of all experimental groups; congener 28 was detected at low levels in some individuals and congeners 47, 99 and 100 were present in all individuals. For many of the PAHs, mean log tissue concentrations were below detectable levels in all or most animals (Fig. 2d and 3d), particularly for those with higher molecular weights.

In the maternal tissues of ewes maintained either constantly on the respective treatments or exposed to sludge-treated pastures for limited periods, either before or after mating, there were no differences with treatment in the mean concentrations of any of the EDCs measured, with the exception of PCB congener 138. Concentrations of this congener were higher in TT than CC animals $(P<0.01)$ (Fig. 2b) but there were no differences between TC and CT animals (Fig. 3b).

While animals of the respective mating groups were not directly comparable subjective observations indicated that concentrations of PCB congeners 28, 52, 153 and 180 were approximately 4 to 15 fold higher in the TC and CT groups relative to the TT and $\mathrm{CC}$ groups while the concentrations of the remaining congeners were broadly similar. On the other hand, concentrations of PBDE congeners 47, 99 and 100 were approximately 4 to 10 fold higher in the $\mathrm{CC}$ and TT animals than in the TC and CT animals. Mean concentrations of phthalate and PAHs did not differ as markedly.

Fetal tissue EDC concentrations. DEHP was detected in all fetal samples and most PCB congeners were present in the majority of fetuses in the continuously exposed group but in fewer of the crossover group, except for congener 28 (Fig. 2 and 3 ). On the other hand, in both the continuously exposed and crossover groups, tissue concentrations of PBDE congeners 153, 154 and 183 were below the limit of detection in almost all fetuses 
and congeners 28 and 100 were undetectable in most fetuses. The incidence of PAHs in fetal tissues was highly variable, depending on the individual compound.

There were no differences with treatment or fetal sex in mean concentrations of DEHP or any of the PCB congeners, in either continuously exposed (Fig. 2) or crossover groups (Fig. 3). However, in the crossover group there was a significant interaction between treatment and sex for PCB congeners $101(P<$ $0.05), 118(P<0.01)$ and $153(P<0.05)$, in each case reflecting higher concentrations in male CT than TC animals.

Amongst the PBDEs there were no effects of treatment or sex except for congener 28 in the continuously exposed group which exhibited higher $(P<0.05)$ concentrations in male than female fetuses and there was a significant interaction $(P<0.05)$ between treatment and sex for congener 99 in the crossover group, reflecting higher concentrations in $\mathrm{CT}$ than $\mathrm{TC}$ males than females but higher levels in TC than CT females.

Mean concentrations of benzo[b]fluoranthene were lower in TT than $\mathrm{CC}$ animals $(P<0.05)$ and benzo $[a]$ pyrene which was higher in CT than TC fetuses but there were no other differences with treatment. Acenaphthalene and benzo $[a]$ pyrene concentrations were higher in female fetuses in the crossover group.

\section{Maternal-fetal comparisons}

There was no significant difference in mean DEHP concentrations between adult and fetal tissues at this stage of development in either the continuously exposed or crossover groups. On the other hand, concentrations of all PCBs were higher $(P<0.001)$ in maternal than fetal liver tissue in the crossover group, with the exception of PCB congener 138 for which there was a similar trend, although not statistically significant $(P=0.1)$. In the continuously exposed animals, the pattern was broadly similar with the exception of PCB 101, concentrations of which were higher $(P<0.05)$ in fetal tissues (Fig. 2b).

There were higher concentrations of PBDE congeners $47(P<$ $0.001)$ and $99(P<0.05)$ in fetal than maternal tissue in the crossover group but no difference in congener 100 . In the continuously exposed group on the other hand, there was a significant difference only for congener 99 for which concentrations were higher $(P<0.001)$ in maternal than fetal tissue.

While the majority of PAHs were present in lower concentrations in fetal than maternal tissue in the continuously exposed group (Fig. 2d), the opposite difference was detected for acenaphthalene $(P<0.05)$ and benzo $[a]$ pyrene $(P<0.001)$ and there was no significant difference in a further five PAHs, all of which were present at relatively low levels. In the crossover group, fetal concentrations of naphthalene $(P<0.001)$ and benzo $[a]$ pyrene $(P$ $<0.01)$ were higher than in maternal tissues. There were no significant differences with age in other PAHs.

\section{Fetal-maternal correlations}

It was not possible to relate individual fetal and maternal tissue concentrations at 55 days gestation owing to the requirement to pool fetal tissues for analysis. The correlations between fetal and maternal liver concentrations for animals of the 110 day and crossover groups were not statistically significant for any of the classes of compound (Table 3).
Table 3 Correlations between maternal and fetal concentrations of chemicals of each class and congener in animals of each experimental group. $n$ per group $=12$

\begin{tabular}{|c|c|c|}
\hline Chemical & 110 days (continuous) & 110 days (crossover) \\
\hline $\begin{array}{l}\text { DEHP } \\
\text { PCB }\end{array}$ & -0.018 & 0.250 \\
\hline \multicolumn{3}{|l|}{ PCB } \\
\hline 28 & 0.264 & -0.165 \\
\hline 52 & -0.342 & -0.075 \\
\hline 101 & -0.119 & 0.433 \\
\hline 118 & 0.195 & 0.129 \\
\hline 138 & 0.034 & -0.049 \\
\hline 153 & -0.303 & 0.505 \\
\hline 180 & -0.155 & 0.220 \\
\hline \multicolumn{3}{|l|}{ PBDE } \\
\hline 28 & 0.133 & 0.161 \\
\hline 47 & 0.228 & 0.105 \\
\hline 99 & 0.035 & 0.164 \\
\hline 100 & 0.068 & 0.155 \\
\hline \multicolumn{3}{|l|}{153} \\
\hline \multicolumn{3}{|l|}{154} \\
\hline 183 & 0.075 & \\
\hline \multicolumn{3}{|l|}{ PAH } \\
\hline Naphthalene & -0.057 & -0.199 \\
\hline Acenaphthalene & 0.067 & 0.080 \\
\hline Acenaphthene & -0.199 & 0.641 \\
\hline Fluorene & -0.093 & 0.121 \\
\hline Phenanthrene & -0.019 & 0.384 \\
\hline Anthracene & -0.215 & -0.073 \\
\hline \multicolumn{3}{|l|}{ Fluoranthene } \\
\hline Pyrene & -0.051 & -0.212 \\
\hline Benzo $[a]$ anthracene & 0.296 & -0.026 \\
\hline \multicolumn{3}{|l|}{ Chrysene } \\
\hline Benzo[b]fluoranthene & 0.183 & -0.063 \\
\hline Benzo[ $k]$ fluoranthene & 0.304 & 0.268 \\
\hline Benzo $[a]$ pyrene & 0.287 & 0.195 \\
\hline \multicolumn{3}{|l|}{ Indeno $[1,2,3-c d]$ pyrene } \\
\hline \multicolumn{3}{|l|}{ Dibenzo $[a, h]$ anthracene } \\
\hline Benzo $[g h l]$ perylene & -0.136 & -0.164 \\
\hline
\end{tabular}

\section{Discriminant analysis comparing day $110 \mathrm{CC}$ and TT groups}

Stepwise discriminant analysis of the data derived from ewe tissues indicated that PCB 138 was important, being consistently selected in all 10 simulated datasets, in discriminating between treatment groups. No further variables were consistently considered important in improving the discrimination between treatment groups.

A similar analysis of fetal data showed that none of the concentrations were consistently selected as important in discriminating between treatment groups. However, either ben$z o[b]$ fluoranthene or benzo[ $k]$ fluoranthene was selected as important in 7 of the 10 analyses on the simulated data; similarly, either PBDE47 or PBDE183 was considered important in 7 of the 10 analyses. These findings suggest that concentrations of each of these pairs might be interchangeable.

\section{Discriminant analysis comparing day 110 CT and TC groups}

Stepwise discriminant analysis of ewe data showed that none of the concentrations were consistently selected as important in discriminating between treatment groups. A similar analysis of fetal data indicated that benzo[a]pyrene was important in discriminating between treatment groups, being selected in 9 of the 10 simulated datasets. No further variables were consistently 
considered important in improving the discrimination between treatment groups.

\section{Discussion}

The measurements of soil concentrations of selected EDCs provide an indication of the relative concentrations of different chemicals to which ewes were exposed when maintained on the respective treatments, at one time point; they are representative of a very much larger group of anthropogenic chemicals that are likely to be in the environment. However, since uptake via the diet or inhaled air is likely to depend on many factors including climatic conditions, time from sludge application, herbage mass, and animal intake as well as the volatility and other chemical characteristics of individual EDCs, precise estimation of exposure would require sophisticated experimentation. Notwithstanding these limitations, collectively, the observed soil EDC profiles suggest that although sludge contains very high concentrations of pollutants relative to inorganic fertiliser, ${ }^{30,31}$ application to pasture resulted in only modest increases in mean environmental concentrations of most of the EDCs measured and, in many cases, did not result in any obvious increase relative to background levels. These trends are consistent with previous reports of patterns of soil EDC concentrations following sludge application. $^{8}$

As observed previously in studies involving similar treatments, ${ }^{12}$ tissue accumulation of pollutants was similar in sludgeexposed animals (TT) compared with controls (CC) although there were trends towards higher PBDE and PAH concentrations in TT than CC animals. However, this study extends previous observations, ${ }^{12}$ showing that concentrations were also similar in the CT treatment relative to the TC treatment animals, despite the fact that the former had been exposed during the period immediately before slaughter. The absence of differences between TT and CC animals and between TC and CT animals, in conjunction with the apparent differences in concentrations with mating group, suggests that, when measured some months after sludge application to pasture, the pattern of accumulation of EDCs in liver is not determined by the treatment i.e. there is no visible effect on the long-term body burden of EDCs and therefore no obvious additional risk to human consumers of sheep liver.

In addition to environmental concentrations, fetal tissue exposure is likely to depend also on the duration of exposure and rates of maternal and fetal uptake, excretion, and metabolism, each of which may differ with stage of gestation. Tissues derived from ewes and fetuses slaughtered at 55 and 110 days gestation were broadly, but not directly, comparable since animals of the respective treatment groups were maintained on the same plots, but were slaughtered at different times. However, it is noteworthy that fetal liver concentrations appeared generally higher at the earlier stage of gestation, perhaps indicating a lesser detoxification capacity. This contrasts with some observations of human fetuses from the latter half of gestation ${ }^{21}$ which indicated no change in tissue concentrations with gestational age. However, others have shown some EDCs changing with fetal age; e.g. two liver PAHs increased and two decreased across the second trimester. ${ }^{32}$ Irrespective of the precise pattern of EDC accumulation, it is clear that tissue accumulation does occur at this time and in view of the high degree of sensitivity of animals at earlier stages of development, further investigation of the tissue burdens at earlier stages is needed.

As previously shown, exposure to sludge-treated pastures before and after mating did not affect liver EDC burden (CC vs. TT) but the current study extends these observations and suggests that the mobilisation of adipose tissue reserves in animals previously exposed to increased EDC burdens did not add significantly to the pollutant burden in other tissues (CT vs. TC).

All of these observations appear anomalous since this type of exposure to sludge, and associated pollutants, is known to be associated with perturbations of multiple physiological systems in fetal or adult sheep. ${ }^{14,16-18,23}$ The result may be explicable in terms of rapid adaptation of liver enzyme systems in exposed sheep resulting in effective degradation of pollutants and only transient increases in tissue exposure. While the uptake, metabolism and tissue partitioning of individual pollutants are poorly understood, it has been shown, in rodent studies, that tissue redistribution of at least one EDC group (PAHs) can occur within hours of exposure. ${ }^{33}$ It follows, therefore, that if the highest levels of exposure occurred some time before slaughter, effects of differences in exposure might not be apparent in tissue concentrations.

The apparent differences between experiments in tissue EDC concentrations are suggestive of different patterns of transient, non-dietary, exposure to EDCs during the weeks immediately before slaughter, all groups having been maintained on the same treatment and control plots and therefore being exposed to similar dietary inputs. Such differences could reflect changes in concentrations in inhaled air as a result of remote emissions or in the availability of EDCs applied in the sludge, as a result of changing temperature or other climatic factors.

Our observations highlight the need to measure exposure at the time of specific developmental events, perhaps through contemporary measurement of blood concentrations, although it is logistically difficult to collect fetal blood. It also suggests that the effects of environmental insults that are not related to exposure to sludge-treated pasture may be of much greater biological significance than the sludge exposure. This has important implications for the assessment of risk to consumers of animal products derived from sludge-treated pastures.

It appears that liver concentrations at the time of slaughter may not provide a physiologically meaningful index of the insult at the time of exposure, despite the fact that tissue concentrations of pollutants are considered to be a much more accurate index of exposure than environmental concentrations. ${ }^{27}$ Furthermore, the contrasting patterns of maternal and fetal EDC accumulation, and the different relationships between them at 55 and 110 days of gestation, suggest that the relationship between maternal EDC exposure and fetal tissue accumulation is highly complex and that fetal insult at one stage of gestation cannot be extrapolated to another. Neither can the relationships be extrapolated between classes of EDC. Specifically, while most PCBs were lower in fetal than maternal tissue at 110 days gestation, some PBDEs and PAHs exhibited the opposite pattern and DEHP was similar in both adult and fetal tissue. By contrast, at 55 days gestation, there appeared to be higher concentrations of DEHP and lower PCB in the fetal tissue while PBDE and $\mathrm{PAH}$ 
concentrations were similar. These observations confirm previous findings ${ }^{12}$ insofar as they show that the fetus can preferentially accumulate certain pollutants. In the earlier study of organic pollutants Rhind et al. ${ }^{12}$ found DEHP and PCB congener 101 to be preferentially accumulated in fetal tissue while in the present study, DEHP was not lower in the fetal than maternal tissue and PCB 101 was elevated in the fetus, i.e. current findings are broadly consistent with the previous observations. On the other hand, fetal PBDE concentrations were not elevated in fetuses in the previous study, in contrast to the current results. Considering the data from all of the studies, together, it is clear not only that it is not possible to extrapolate from maternal to fetal patterns of exposure to EDCs but also that the rates of accumulation in the respective tissues depend on the precise conditions (rates and times of exposure, climatic conditions, etc.) during the period of study.

The absence of significant correlations between maternal and fetal concentrations of pollutants reinforces the conclusion that prediction of fetal exposure from maternal EDC burden is not possible. This has important implications for assessment of risk associated with exposure to EDCs and suggests that estimates of fetal tissue exposure such as those based on maternal milk or cord blood concentrations ${ }^{24,25}$ should be treated with caution. The lack of relationship is probably a reflection of the fact that fetal tissue concentrations are a function not only of maternal EDC uptake, metabolism and excretion but also of the efficiency of transfer across the placenta and of fetal metabolism and excretion, as well as the degree of recycling of EDCs between the fetus and its amniotic fluid.

The results of discriminant analyses do not support the concept of a single chemical, or class of chemical, being responsible for the observed biological responses following exposure to sludge-treated pastures. However, they suggest that with particular combinations of compounds, such as those to which animals were exposed in each of the experimental groups, one or more compounds may be particularly influential. The fact that patterns of tissue exposure to the many EDC classes seem to be inherently unpredictable means that identification of the most biologically significant chemical is difficult. The problem is compounded by the fact that mixtures of EDCs behave unpredictably and can act synergistically or additively. ${ }^{34,35}$

It is concluded that exposure to pastures fertilised with sewage sludge, at rates previously shown to result in physiological perturbations in sheep, was not associated with increased maternal or fetal liver concentrations of selected EDCs irrespective of the stage of development at which they were measured and of maternal tissue mobilisation and EDC release during gestation. The patterns of tissue accumulation differed between adults and fetuses in an inconsistent manner and maternal and fetal burdens were poorly correlated. Furthermore, it was not possible to discriminate, consistently, between treatments on the basis of any one EDC. Thus, retrospective measurements of EDC tissue burdens could not be used to accurately assess fetal EDC insults.

\section{Acknowledgements}

The assistance of Messrs J. MacDonald and G. Corsar of Hartwood Research Station in the management of the animals is gratefully acknowledged. This work was funded by the Wellcome Trust (grant number 080388) and the Rural Environment Research and Analysis Department of the Scottish Government. The valuable comments of Dr Kevin Sinclair on the manuscript are gratefully acknowledged.

\section{References}

1 T. Colborn, A. M. Vom Saal and A. M. Soto, Environ. Health Perspect., 1993, 101, 378-384.

2 S. M. Rhind, Reprod. Domest. Anim., 2005, 40, 282-290.

3 IEH, IEH Assessment of the Ecological Significance of Endocrine Disruption: Effects on Reproductive Function and Consequences for Natural Populations (assessment A4), MRC Institute for Environment and Health, Leicester, UK, 1999.

4 L. J. Guillette, T. S. Gross, G. R. Masson, J. M. Matter, H. F. Percival and A. R. Woodward, Environ. Health Perspect., 1994, 102, 680-688.

5 J. J. Heindel, D. K. Gulati, R. C. Mounce, S. R. Russell and J. C. Lamb, Fundam. Appl. Toxicol., 1989, 12, 508-518.

6 R. J. Hussain, J. Gyori, A. P. DeCaprio and D. O. Carpenter, Environ. Health Perspect., 2000, 108, 827-831.

7 S. R. Smith, in Agricultural Recycling of Sewage Sludge and the Environment, ed. S. R. Smith, CAB International, Wallingford, 1996, ch. 10, pp. 207-236.

8 S. M. Rhind, A. Smith, C. E. Kyle, G. Telfer, G. Martin, E. Duff and R. W. Mayes, J. Environ. Monit., 2002, 4, 142-148.

9 R. Duarte-Davidson and K. C. Jones, Sci. Total Environ., 1996, 185, 59-70.

10 S. M. Rhind, C. E. Kyle, G. Telfer, E. I. Duff and A. Smith, Environ. Health Perspect., 2005b, 113, 447-453.

11 S. M. Rhind, C. E. Kyle and J. Owen, Anim. Sci., 2005a, 81, 107-113.

12 S. M. Rhind, C. E. Kyle, C. Mackie and L. McDonald, J. Environ. Monit., 2009, 11, 1469-1476.

13 M. Bellingham, P. A. Fowler, M. R. Amezaga, S. M. Rhind, C. Cotinot, B. Mandon-Pepin, R. M. Sharpe, C. E. Kyle and N. P. Evans, Environ. Health Perspect., 2009, 117, 1556-1562.

14 C. Paul, S. M. Rhind, C. E. Kyle, H. Scott, C. McKinnell and R. M. Sharpe, Environ. Health Perspect., 2005, 113, 1580-1587.

15 P. A. Fowler, H. Dora, M. R. McFerran, M. R. Amezaga, D. W. Miller, R. G. Lea, P. Cash, A. S. McNeilly, N. P. Evans, C. Cotinot, R. M. Sharpe and S. M. Rhind, Mol. Hum. Reprod., 2008, 14, 269-280.

16 H. Erhard and S. M. Rhind, Sci. Total Environ., 2004, 332, 101-108.

17 P. M. Lind, M. Gustavsson, S. Hermsen, S. Larsson, C. E. Kyle, J. Örberg and S. M. Rhind, Sci. Total Environ., 2009, 407, 2200-2208.

18 M. R. Amezaga, M. Bellingham, N. P. Evans, C. Cotinot, R. M. Sharpe, S. M. Rhind, A. S. McNeilly and P. A. Fowler. Proc. Soc. Reprod. Fertil., Society for Reproduction and Fertility, Edinburgh, 2008, p. 68.

19 U. Bosse, N. Bannert, K. H. Niessen, M. Teufel and I. Rose, Zbl. Hyg., Gustav Fischer Verlag, Stuttgart, 1996, pp. 331-339.

20 E. P. Dekoning and W. Karmaus, J. Exposure Anal. Environ. Epidemiol., 2000, 10, 255-293.

21 A. Schecter, S. Johnson-Welch, K. C. Tung, T. R. Harris, O. Papke and R. Rosen, J. Toxicol. Environ. Health, 2007, 70, 1-6.

22 J. Doucet, B. Tague, D. L. Arnold, G. M. Cooke, S. Hayward and C. G. Goodyer, Environ. Health Perspect., 2009, 117, 605-610.

23 A. Suvorov and L. Takser, Environ. Health, 2009, 7, 58.

24 F. Dallaire, E. Dewailly, G. Muckle and P. Ayotte, Environ. Health Perspect., 2003, 111, 1660-1664.

25 D. B. Barr, A. Bishop and L. L. Needham, Reprod. Toxicol., 2007, 23, 260-266.

26 R. M. Bigsby, A. Caperell-Grant and B. V. Madhukar, Cancer Res., 1997, 57, 865-869.

27 J. P. Meador, L. S. McCarty, B. I. Escher and W. J. Adams, J. Environ. Monit., 2008, 10, 1486-1498.

28 Great Britain Parliament, The Sludge (Use in Agriculture) Regulations, 1989, Statutory Instruments (1989), no. 1263, Her Majesty's Stationary Office, London, 1989.

29 Lawes Agricultural Trust, Genstat 5 Committee, Genstat 5 Release 3, Reference Manual, Clarendon Press, Oxford, 1994. 
30 E. Z. Harrison, S. R. Oakes., M. Hysell and A. Hay, Sci. Total Environ., 2006, 367, 481-497.

31 J. L. Stevens, G. L. Northcott, G. A. Stern, G. T. Tomy and K. C. Jones, Environ. Sci. Technol., 2003, 37, 462-467.

32 P. A. Fowler, S. Cassie, S. M. Rhind, M. J. Brewer, J. M. Collinson, R. G. Lea, P. J. Baker, S. Bhattacharya and P. O'Shaughnessy, J. Clin. Endocrinol. Metab., 2008, 93, 619-626.
33 J. R. Withey, J. Shedden, F. P. C. Law and S. Abedini, J. Appl. Toxicol., 1992, 12, 223-231.

34 A. Kortenkamp, Environ. Health Perspect., 2007, 115(Suppl 1), 98105.

35 K. L. Howdeshell, V. S. Wilson, J. Furr, C. R. Lambright, C. V. Rider, C. R. Blystone, A. K. Hotchkiss and L. E. Gray, Toxicol Sci., 2008, 105, 153-165. 